\title{
Suggested Pro-development Special and Differential Treatment Arrangements and Measures
}

Devising pro-development special and differential treatment arrangements and measures to ensure that they make a difference in services competitiveness and result in increased exports of small and low-income countries is very challenging and one of the reasons that consideration of SDT has often remained in the realm of best endeavours or exhortatory clauses. To be effective, however, SDT arrangements and measures must have a concrete impact and help to improve either the competitiveness of developing country services exporters or their market access opportunities.

After having reviewed the suggestions and recommendations made in many papers by WTO members, academics and policy-makers, ${ }^{55}$ we set out below proposals for ways in which SDT measures could be translated into real benefits for Commonwealth small and low-income countries negotiating RTAs covering trade in services. These measures could be discussed and implemented in the context of any type of trade agreement, whether at the WTO or in RTAs.

The pro-development SDT measures proposed below for the benefit of small and low-income countries include those that may be viewed as independent of the actual content of commitments made during the negotiations, as well as those that may form part of negotiated outcomes in trade agreements. Since negotiated outcomes in the services area always contain non-reciprocal elements, the SDT-related component of these outcomes would be important and is highlighted below (such as for Mode 4). Some negotiated outcomes, though important for parties at all levels of development (such as for Mode 1), may have a particular stimulus on developing country services exports and so these are also included.

\subsection{Negotiated outcomes that are beneficial to developing country partners}

Given the smaller sizes and lower levels of development of developing countries, their services exporters have a comparative advantage particularly in two of the four modes of supply, namely Modes 1 and 4. We therefore recommend that an effort be made to reach negotiated outcomes in trade agreements that will allow for a favourable situation for their suppliers in both of these modes.

\subsubsection{Binding of Mode 1 in RTAs by developed countries for all services exports and removal of linkage with Mode 3}

A legally bound outcome of openness for cross-border supply of service exports into developed country markets serves the very important goal of modal neutrality so that 
developing country exporters can market their services via the internet rather than through commercial establishment. This is important because the cost of exporting services cross-border for a given service should be less for the lower-cost producer. However, if the cross-border export is tied to a commercial presence through being linked to Mode 3, as it is in many developed countries' GATS schedules, this would put it out of reach of the majority of service suppliers in the smaller and poorer countries. The binding of Mode 1 is thus critical for Commonwealth countries for which virtually all exporting firms are micro, small and medium-sized enterprises, as well as for individual suppliers which have neither the critical mass of capital to invest abroad nor the ability to maintain an overseas commercial activity..$^{56}$ The guarantee of openness in Mode 1 can directly affect the competitiveness of these exporters from small and low-income countries and their ability to insert themselves into world markets. We therefore view this desirable negotiated outcome as a form of SDT, since it would be relatively more favourable for developing countries. The goal of across-the-board binding of cross-border services trade for all sectors by developed countries, without linkage to Mode 3, should therefore be a key objective for Commonwealth countries in their negotiations with RTA partners. The goal of modal neutrality was emphasised in the Hong Kong Ministerial Declaration, which advocates the 'delinking' of Modes 1 and 3 for service suppliers. ${ }^{57}$

Of course, in practice there are few restrictions on Mode 1 supply, even where there are no formal market-opening commitments. But bindings would 'lock-in' the current practice and ensure against back-sliding in the future. ${ }^{58}$

\subsubsection{Market access commitments for Mode 4 in categories of interest to developing countries}

The negotiated outcome of trade agreements with respect to Mode 4, the movement of natural persons, is of even more critical importance to small and low-income developing countries. A number of studies have predicted that enormous welfare gains would result from the developed countries opening Mode 4 even to a quite limited extent. ${ }^{59}$ Though most of the small and low-income countries do not have large populations, nonetheless without exception they have people who would benefit from opportunities to work temporarily abroad. ${ }^{60}$ And while the 'brain drain' aspect can be of concern and should not be overlooked, several studies have shown that remittances can more than offset this loss for the country as a whole, at least in financial terms. ${ }^{61}$

The guarantee of greater access in Mode 4 to a larger number of categories of workers can directly affect the competitiveness of small and low-income countries and their ability to penetrate world markets through the movement of their people. We view this as a highly desirable negotiated outcome in RTAs and suggest that this be pursued as another key objective for small and low-income Commonwealth countries in negotiations with their trading partners. ${ }^{62}$ The authors acknowledge that for both political and security reasons the developed countries are not likely to commit to broad opening 
of Mode 4 in the near future. Thus the most practical way of proceeding is to suggest gradual steps toward greater opening through incremental measures, i.e. expanding the numbers and time periods allowed for existing categories, facilitating movement of professional workers through agreements on the equivalency of qualifications and increasing the number of semi-skilled categories that are included in trade agreements.

More specifically, we consider the following as desirable outcomes for Mode 4:

\section{Inclusion in trade agreements of broader categories of workers, namely contractual service suppliers, independent professionals and trainees}

Commonwealth countries should focus on the guaranteed inclusion in RTAs of categories of greater interest and relevance to their workers, including those in particular that are not tied to a commercial presence abroad, namely: contractual service suppliers, independent professionals and trainees. These are the types of skilled workers that are most likely to benefit from expanded Mode 4 access for small and low-income countries. Additionally, as long a time period of stay as can be obtained should be requested for these categories (with a target of two to three years), with the possibility of renewal of the initial period.

\section{Inclusion of technicians}

In addition to the skilled categories of workers discussed in the preceding section, Commonwealth countries should request the inclusion of relevant categories of technicians or semi-skilled workers in Mode 4 commitments with their RTA partners, particularly those workers in which they would have a comparative advantage (for example construction workers, health care workers, masseurs, sports players, musicians and fashion models). If there is reluctance on the part of RTA partners to bind these categories without limits, then annual quotas should be sought.

\section{Agreement upon spouses and pension portability}

Issues that are related to the worker categories mentioned above and the temporary stay in RTA partners should be negotiated and included in the agreed commitments, as far as possible. These issues would include the guarantee of the right of spouses to accompany the worker in question and possibly also to work (as Australia has already done in two of its RTAs, with China and with ASEAN), as well as the issue of pension portability between home and host countries. It is easier to reach agreement on these issues in an RTA context than in a multilateral context.

\section{Incorporation of elements from bilateral labour agreements into RTAs}

Commonwealth countries could suggest the inclusion of elements from bilateral labour agreements into RTAs. This could cover various issues such as agreement to allow a specified number of low-skilled workers from Commonwealth countries access to the markets of their RTA partners on a seasonal basis. For implementation, this would involve creation of organised programmes through dedicated ministries on both 
sides, annual agreement on quotas subject to the needs of the labour market and shared monitoring mechanisms.

\section{Establishment of a list of occupations with relevant criteria for undertaking development-oriented commitments}

In addition, we would support the suggestion made by the UNCTAD Secretariat in a 2003 study $^{63}$ to establish a list of occupations, and associated skill qualifications and experience that could be adapted to individual countries' needs and to propose these categories as first priority occupations linked to services for the undertaking of Mode 4 commitments. For these occupations and sectors, market access as provided for in national legislation should be bound at the level of current access for temporaryemployment-based visas and work permits, or at expanded levels of access. Economic needs tests should not be applied to these occupations. ${ }^{64}$

\section{Obligation for pre-screening, verification and monitoring on the part of labour- sending countries}

Another possibility for promoting the greater movement of labour from Commonwealth small and low-income countries would be to place an obligation on source countries to carry out pre-screening and selection of workers within an agreed profession or skill level, thus absolving the recipient country from this burden. Additional obligations to verify the identity and background of temporary workers and to monitor the situation, together with the recipient country, while they are abroad, with a commitment to facilitate their return and combat illegal migration, would be useful steps, and might induce developed countries to grant greater access. This type of shared responsibility already exists in bilateral labour agreements, but has not yet been incorporated into regional trade agreements. The possibility of imposing fines upon the sending country for workers who overstay their stay or giving premiums to workers who comply with visa limits, with the possibility of rewarding them with future temporary stays in the recipient countries, would also be helpful. ${ }^{65}$

\section{Development of disciplines for the use of economics needs tests}

More effective approaches to address measures inhibiting Mode 4 market openings for service suppliers from developing countries could include ways to more effectively address ENT measures. These could involve the negotiation of binding rules spelling out the conditions for the application of ENTs included in services schedules, as well as mechanisms for their periodic review, in order to reduce the arbitrary and nontransparent nature of their application.

\section{Negotiation of mutual recognition agreements}

The negotiation of mutual recognition agreements should also be encouraged as a means of providing greater access for service suppliers under Mode 4, particularly to facilitate the movement of professional workers from developing countries to developed 
country markets. Though this is a component of the GATS (Article VII), this objective could be strengthened under RTAs, while recognising that it is a particularly challenging undertaking among countries at different levels of development.

\section{Longer timeframes for implementation of obligations}

As part of the negotiated outcome of trade agreements, Commonwealth small and lowincome countries should seek longer timeframes for implementation of obligations for their services commitments. However, it should be kept in mind that flexibility in these obligations can work both ways; it can be beneficial when taken advantage of appropriately, but on the other hand can delay necessary regulatory reform by allowing non-action. Thus the request for longer timeframes for implementation of liberalising obligations for service sectors within RTAs by Commonwealth countries should be pursued along with specific commitments to provide technical assistance for regulatory reform and the creation or strengthening of regulatory agencies in these sectors.

\subsubsection{Government procurement}

A recent presentation by a member of the WTO Secretariat indicated that more than 70 per cent of the RTAs notified to the WTO contain provisions on government procurement (Muller, 2010). Some of these provisions cover services as well as goods. ${ }^{66}$ To the best of our knowledge most, if not all, of these agreements provide reciprocal access, i.e. each party provides government procurement opportunities on a roughly balanced basis to the other parties. However, there is no reason why a poorer country negotiating an FTA should not request government procurement opportunities on a non-reciprocal basis, granting more limited access, or even none at all, to the developed country parties with respect to its own government procurement market. Of course it would be important to ensure that the thresholds for access were low enough for service suppliers in small countries to be able to take advantage of the opportunities.

\subsection{Channels for sharing information and expertise}

Agreement on the creation of effective channels and programmes for the dissemination of information and sharing of expertise is another important way that SDT can help the medium- to long-term goal of stimulating services exports from small and lowincome Commonwealth countries. The smaller countries that are members of the WTO have access to the contact and enquiry points established under Articles III.4 and IV.2 of the GATS ${ }^{67}$ Any non-members that are negotiating an RTA might request that the agreement give them the right of access to these points on behalf of themselves and their service suppliers.

Exchange programmes for trade officials are an excellent means of providing expertise through the building of human capital. This exchange of trade officials could include, inter alia, assistance with the analysis of statistical data on trade in services, assessment of the interests in and gains from services trade by the officials in the 
countries where they are being hosted, and the identification of service sectors of export interest and negotiating priorities for the country in question, all of which are of crucial importance for the ability to participate effectively in trade negotiations and in promoting services competitiveness at home. However, there are not many examples of such programmes that include the provision of technical expertise along with funds for capacity-building.

One innovative approach is contained in recent RTAs concluded by the USA with the Dominican Republic and five Central American countries (DR-CAFTA) and with Peru, that include for the first time the requirement to provide capacity building as part of the implementation of the agreement. Article 19.4 of DR-CAFTA and Article 20.4 of USA-Peru recognise that 'trade capacity building assistance is a catalyst for the reforms and investments necessary to foster trade-driven economic growth, poverty reduction and adjustment to liberalised trade'. To ensure that capacity building will be provided, the agreement establishes a committee on trade capacity building (TCB). The functions of the committee are to:

(a) Seek the prioritisation of trade capacity building projects at the national or regional level, or both;

(b) Invite appropriate international donor institutions, private sector entities and non-governmental organisations to assist in the development and implementation of trade capacity building projects in accordance with the priorities set out in each national trade capacity building strategy;

(c) Work with other committees or working groups established under the agreement, including through joint meetings, in support of the development and implementation of trade capacity building projects in accordance with the priorities set out in each national trade capacity building strategy;

(d) Monitor and assess progress in implementing trade capacity building projects; and

(e) Provide a report annually to the Commission describing the committee's activities.

Technical assistance through capacity-building activities and technical experts is to be provided in response to needs identified by the recipient countries in their national action plans, to which donors are asked to respond with ideas and financing for projects. ${ }^{68}$ The trade capacity building effort covers all aspects of trade policy, including services. Each developing country party to the agreement is required to periodically update and provide to the committee its national trade capacity building strategy in its national action plan. Meetings of the TCB committees are held on a regular basis, normally twice a year, and attended by representatives of each of the member countries and of the Inter-American Development Bank (IDB), the World Bank, the Organization of American States (OAS) and the Economic Commission for Latin America and the Caribbean (ECLAC), which allows for a review of updates of identified needs and priorities in the recipient members' trade capacity building strategies as well as 
responses to these needs through the activities of US donor agencies and international institutions. The USA provided over US $\$ 80$ million in TCB assistance through bilateral and regional assistance programmes to the CAFTA-DR countries in 2008 from a broad spectrum of US donor agencies (independently from the assistance given by the international institutions) ${ }^{69}$ To our knowledge, no review has yet been undertaken to determine the effectiveness of this approach to trade capacity building.

The FTAs negotiated between the USA, on the one hand, and Colombia and Panama, on the other, contain similar provisions, but at the time of writing they had not been ratified by the US Congress.

A different approach that can also be cited as an example of trade capacity building is the 'Hub and Spokes' project of the Commonwealth Secretariat, which was proposed by the Secretariat and taken on by the EU as part of its assistance to the African, Caribbean and Pacific (ACP) countries. It is designed to strengthen capacity at the regional and national levels for all ACP regions and countries on WTO, EPA and general trade matters. The programme is funded mainly by the European Commission with contributions from the Commonwealth Secretariat and the Organisation Internationale de la Francophonie. Of the 79 ACP countries, 55 are within the area covered by the project and are eligible for project support, with the Secretariat having responsibility for the Pacific and Caribbean regions as well as East and Southern Africa, and the Organisation Internationale de la Francophonie for West and Central Africa. ${ }^{70}$ The first, four-year, 'Hub and Spokes' project ran from 2004-2009 at a cost of $€ 17$ million. With widespread support for a successor programme, the Secretariat is working closely with project partners to design a Phase II programme, and the second component of this project should be underway in 2011..$^{71}$

The primary purpose of the 'Hub and Spokes' project is to assist smaller and lowerincome ACP countries in the following four areas so that they can better participate in and draw advantages from the multilateral trading system and regional agreements:

- Improvement of trade policy formulation skills;

- Development of trade analytical, negotiation and implementation skills;

- Broader knowledge of multilateral and regional trade policy issues;

- Greater involvement of stakeholders in discussions and policy formulation.

The project operates through the identification of expert regional trade policy advisors (RTPAs) and trade policy analysts (TPAs) as well as administrative assistants (AAs) from Commonwealth countries, proposed to recipient countries as resident experts. Once accepted, these experts are placed for a specific length of time - between one and three years - in the Ministry of Trade of the recipient ACP country that is in need of expert assistance. These experts may work in any area of trade policy, including services. During 2009, the project placed six RTPAs, 19 TPAs and six AAs in 25 countries as well as five in regional secretariats. 
A mid-term review was carried out of the 'Hub and Spokes' project in 2007, which found the project to be efficient, practical and relevant, and to have a positive impact. It found that the experts had contributed to a wide range of capacity-building activities, working jointly with local policy officials, including preparation and drafting of technical papers and briefs, as well as informal papers and working documents; drafting national trade policy statements; conducting detailed research and cost-benefit analysis on negotiating approaches; backstopping for participation in trade negotiations; and contributing to preparations for implementing trade agreements through sensitising key stakeholders to trade policy issues. The review states that:

The smooth running of this project is illustrated by the successful recruitment, retention and achievement of the RTPAs/TPAs in the field. This would suggest that the hard work has been done and now the management committee's roles and functions should be more geared to maintaining support to the project and its partners. ${ }^{72}$

We endorse these two approaches to capacity building for trade as concrete examples of what would be useful to replicate and incorporate into future trade agreements in the services area negotiated by Commonwealth small and low-income countries. In fact, we advocate a combination of elements from both approaches. Such capacity building programmes should be agreed as part of the overall outcome of any RTA. Key elements to underline as critical components of the success of these programmes are the definition of needs and priorities by the developing country partner, the creation of a committee on trade capacity building to monitor agreed efforts, the identification of experts acceptable to the partner country and their actual embedding into national ministries of trade for a sustained period of time, as well as the unconditional financing of the programme by either the partner country alone or in combination with international financial institutions.

\subsection{Provision of effective technical assistance}

\subsubsection{The design and implementation of services regulatory systems}

Technical assistance in the context of services reform is critical. Developing countries, especially small and low-income ones, lack the necessary expertise to design appropriate regulatory instruments for their infrastructure services and the technical expertise to implement them. This makes the liberalisation of key service sectors such as telecoms, financial services, transport, distribution and energy highly problematic, despite the wishes of developing countries to move forward. ${ }^{73}$ Building regulatory capacity, particularly for those infrastructure services sectors characterised by market failures such as those where imperfect competition is the norm and that tend to monopolies - the case of all network services, including telecommunications, transport and energy - or those where imperfect knowledge is the norm and where consumers need to be protected such as financial and healthcare services - must be a critical component of services 
liberalisation undertaken by developing countries. The draft of an appropriate regulatory framework with adequate laws and regulations is the first step in such a process. However, it is often necessary as well to create and/or strengthen regulatory agencies and train personnel. This building of regulatory capacity requires a more sustained effort than simply a few days of workshops or seminars. Effective technical assistance in this area would involve commitments on the part of developed trading partners in specific sectors to send an expert for several months or a year to draft or improve laws and help set up or strengthen the functioning of a regulatory agency.

One of the major weaknesses in the SDT area is the 'best endeavour' nature of most forms of SDT in the WTO documents and the RTAs. This is particularly the case for technical assistance. This lack of obligation to provide technical assistance by developed trading partners has meant that in practice nothing is usually done beyond a few informational and training seminars. There is no long-term, practical effort to make a difference on the ground where it really counts. One of the best ways to make technical assistance more effective would be to link it to market-opening measures or commitments agreed on the part of the developing countries. This would require a change in the way that technical assistance commitments are negotiated, converting them from 'best endeavours' to bound obligations and recording them on a sectoral basis as an integral part of all services commitments.

Under this approach, after careful assessment of domestic needs and requirements for liberalisation, a developing country would request technical assistance for a particular sector during trade negotiations with its major corresponding developed trading partner. If the response were positive, then the future liberalisation commitment would be incorporated by the developing country into the GATS schedule of commitments for that particular sector in the column under 'additional commitments', together with the agreement to provide technical assistance for specific regulatory reform. For negative list RTAs, this agreement would be included for the measure in question in the annex on non-conforming measures. The outcome of a negotiation for a particular sector would then be composed of the future liberalisation commitment, together with the promise of required technical assistance to make it a reality.

If effective technical assistance were not provided as promised by the developed country trading partner or an international organisation with competence for providing advice and expertise on regulatory reform (such as the World Bank or the International Telecommunications Union), then the developing country would not be required to carry out the specified future liberalisation commitment in that sector.

A precedent for such an approach exists in connection with the negotiations on trade facilitation. In the 'July 2004 Package', the Ministerial Council stated:

It is recognised that negotiations [on trade facilitation] could lead to certain commitments whose implementation would require support for infrastructure development on the part of some Members. In these limited cases, developedcountry Members will make every effort to ensure support and assistance directly 
related to the nature and scope of the commitments in order to allow implementation. It is understood, however, that in cases where required support and assistance for such infrastructure is not forthcoming, and where a developing or least-developed Member continues to lack the necessary capacity, implementation will not be required. ${ }^{74}$

This proposal is reflected in bracketed language in Paragraph 1.4 of Section II of the current negotiating Draft of the Agreement on Trade Facilitation, which provides that:

Members agree that in cases where the required support and assistance is not forthcoming from developed country members and other donors, and where a developing or least-developed country member continues to lack the necessary capacity, implementation will not be required..$^{75}$

If the commitments to provide technical assistance to developed and least-developed countries were transformed from a hortatory to a mandatory basis in the negotiations on services at the WTO and in RTAs, then there would be a legal basis for reverting to the dispute settlement provisions of the WTO in the case of non-compliance. This would be very much a last resort, undertaken only when discussions on an outstanding commitment had failed. However, putting technical assistance promises on the same level as bound commitments should provide the necessary incentive to encourage both sides to take these discussions seriously - the developing countries would have less justification to stall on liberalisation and the developed countries would be placed under the spotlight in order to demonstrate that their actions met the demands of the developing countries.

\subsubsection{Addressing supply-side constraints}

Technical assistance for the smaller and poorer countries could also be directed at the removal of supply-side constraints. Obviously service industries do not face many of the supply-side bottlenecks that inhibit exports of goods, such as lack of access to export financing, high-priced energy, poor roads, inadequate seaport and airport facilities, and slow and inefficient customs procedures. However, there are of course supply-side obstacles that restrict the ability of service industries to export their products. The time and expense of setting up a business is one, as is lack of capital. Poor tourism infrastructure and inadequate telecommunications and transportation are obstacles to growth in an area where many of the poorer countries have great potential. Technical assistance to improve these areas would be a useful goal for the smaller and poorer countries in negotiating RTAs.

\subsection{Recognising and facilitating inter-model linkages in services trade by developing Commonwealth countries}

The positive linkages that exist between the four defined modes of service supply are not recognised in RTA disciplines and commitments. However, the clear distinction 
between the various modes is becoming increasingly blurred and it is clear that service suppliers do not usually avail themselves of only one mode to deliver a service and that often there exists an interdependence across all four GATS modes of supply. According to an OECD study, positive linkages take the form of: (i) complementarities across modes, where one or more mode is simultaneously used in supplying the service across borders; and (ii) facilitation across modes, where trade through one mode creates conditions that are conducive for trading through other modes. ${ }^{76}$ Restrictions on one mode of service supply restrict the possibility for efficient intermodal linkages and can distort the way in which a service is traded.

Although the most common linkage is between Modes 3 and 4, for services exported by developing countries - in particular, information technology and business process outsourcing services and health services - the complementary relationship is between Modes 1 and 4. The recognition within RTAs of this intermodal linkage would allow for the negotiation of commitments that facilitated such linkages in key sectors of export interest to developing Commonwealth countries so that the central modal source of the positive linkage is identified and bound without restriction, and any associated intermodal distortions are minimised. 